\title{
The challenges and possible remedies to poor pedestrian safety considerations along and across Nigerian busy roads
}

\begin{abstract}
This study is an attempt to investigate into the challenges faced by pedestrians using Nigerian roads with the aim of proposing remedies to the poor safety considerations for pedestrians using the Onitsha-Enugu expressway as a case study. The Awka segment of the highway was of interest, since Awka is the Capital city of Anambra State with obvious commercial activities going on at both sides of the busy dual carriage expressway. Due to some financial, environmental and health issues associated with transport, soft modes (walking and/or cycling) have been seen as the most sustainable modes of transportation.1 Pedestrian safety considerations is, therefore, a key aspect of Traffic Engineering. For this study, key sections of the highway with high pedestrian crossing traffic were identified by direct observation, the peak hour volumes of pedestrians at the selected sections were gotten using manual counting. Three locations were critical and they are; Unizik Junction, Regina Junction, and Aroma junction. Vehicular flow at the selected areas was also gotten by manual counting. The highest vehicular traffic flow was observed on Wednesday evenings at Aroma, which was as high as $4690 \mathrm{Veh} / \mathrm{hr}$ for both straight ahead movements and turning. At the same time, a volume of 1431 pedestrians was counted at Aroma which is high, pointing to the fact that crossing difficulties would be experienced by pedestrians at that intersection. At Unizik junction, up to $34 \%$ of the pedestrians still prefers to cross on the carriageway instead of using the pedestrian bridge. At the Regina Junction, no crossing facility was provided. An assessment of Pedestrian safety considerations at these locations was made and they were found to be either unacceptable, inadequate, and/or inefficient which is typical for all classes of Nigerian roads. It was recommended that Nigerian Government at all levels needs to overcome these decades of street and road construction projects that have routinely ignored the provision of facilities that would resolve pedestrian related issues on our highways.
\end{abstract}

Volume 2 Issue I - 2017

\author{
Chidozie M Nwakaire,' Destiny E Chuku,' \\ Jonathan N Udemba ${ }^{2}$ \\ 'Department of Civil Engineering, NnamdiAzikiwe University, \\ Nigeria \\ ${ }^{2}$ National Inland Waterways Authority Warri, Nigeria
}

Correspondence: Chidozie M Nwakaire, Department of Civil Engineering, NnamdiAzikiwe University, Nigeria,

Email cm.nwakaire@unizik.edu.ng

Received: December 21, 2016 | Published: February 08, 2017

Keywords: pedestrians, traffic, accidents, vehicles, sidewalks crossing

\section{Introduction}

A pedestrian is a person travelling on foot, whether walking or running on a road pavement. Walking has always been the primary means of human locomotion. Walking as a form of exercise is essential to the wellbeing of man..$^{2}$ To an engineer, the need to increase the amount of people walking (pedestrians) has a relationship to the amount of traffic volume expected on the highway. The greater the number of people walking, the lesser the number of cars, hence, less the traffic. Hence for obvious necessities, the act of walking or running should be encouraged by factoring pedestrians into the process of highway design.

\section{The merits of Pedestrianization and pedestrian movement}

Frequent exercise such as walking, running, skating etc. tends to reduce the chances of obesity, stroke, coronary heart disease, and other related medical problems. ${ }^{2}$ This as a result will reduce the need for acute health care costs and improved quality of life. Use of cars for short distances or short trips tends to contribute to vehicle emission which leads to climate change. These cars make use of fossil fuels and as a result, oxides of Carbon and Nitrogen which are emitted from the exhaust of vehicles is a major greenhouse gas. ${ }^{3}$ Emissions from vehicles are great contributors to environmental air pollution both at local, transboundary and global levels. ${ }^{4}$ Vehicles are also a major contributor of noise pollution in the society. Noise from car horns and moving vehicles can be so loud creating discomfort to people. Heavy vehicles are major contributors to pavement failures ${ }^{5}$ but when the volume of private cars becomes high, they can also contribute to pavement failure by their combined weight effect, more so when such volume results in frequent congestion. Walking and bicycling are affordable forms of transportation. It saves money spent on fuel, repairs of damaged parts, change of worn-out parts meaning that people would have more money to save or spend on other things. It could ultimately lead to a reduction in road accidents. When the number of people walking increases, the numbers of vehicles using the roads are reduced, traffic density is reduced leading to a free flow where drivers choose their operating speeds based on their intuition and the need to overtake or avoid other vehicles is also reduced. Ultimately leading to a reduction in car crashes ${ }^{6,7}$ It leads to a reduction in the demand for vehicle parking space. Most importantly, it is more flexible than movement by vehicles.

\section{Pedestrian safety}

As with every mode of travel, there is clearly some risk associated with walking. However, walking remains a healthful, inherently safe 
activity for inestimable number of people every year. The public health community recognizes that lack of physical activity and a decline in bicycling is a major contributor to the hundreds of deaths caused by heart attacks and strokes. ${ }^{2}$ Therefore, it is essential that movement of pedestrians on highways should be made safe, comfortable and fun to encourage more people who could walk short distances do so and leave their cars parked inside. Various organizations have aimed through concerted efforts to advocate campaign and enlighten both pedestrians and governmental institutions on the need to make the roads safer. It is alarming the number of deaths recorded on Nigerian highways which involves pedestrians on a daily bases. Below are some of pedestrian related crashes and deaths statistics recorded in various countries around the world. Though Nigeria does not have the monopoly of this menace as even the developed countries of the world are still developing in this aspect. For instance, in 2001, the United States recorded 4,901 pedestrian deaths and 78,000 pedestrian injuries. In 2013, they recorded less, 4735 pedestrian deaths and 66,000 injuries involving pedestrians. This averaged to one crashrelated pedestrian death every 2 hours. Additionally, more than 150 000 pedestrians were treated in emergency departments for non-fatal crash related injuries in 2013. ${ }^{3}$ In Ghana, pedestrians make up about $43 \%$ of the deaths recorded on roads. In the United Arab Emirates pedestrians make up about $28 \%$ of deaths recorded on roads. It was reported to be highest in El Salvador and Liberia with about $62 \%$ and $66 \%$ of pedestrian deaths recorded.$^{8,9}$ In 2012, ${ }^{10}$ reported a total of 3, 260 recorded pedestrian deaths were recorded in Nigeria. This record is obviously far below the fact. The fact is that the accident monitoring and reporting system in Nigeria is as inefficient as the remedies provided.

Pedestrians are over represented in the crash data. However, there are no reliable sources of information for professionals to know how long pedestrians are exposed to motor vehicle traffic to fully understand the issues related to pedestrian crashes and accident. Some perturbing questions include: How many minutes or hours do people spend walking or crossing the streets? How many miles do people walk in a day, month or year? What proportion of people is walking, bicycling or skating? Where are they walking? Some of these questions brought the burden for this study along the most major and important road that passed the Awka city. Reduction in pedestrian crashes could be attributed to the probability of fewer people walking in general, improvements in facilities, law enforcement, education, or behavior of the people walking. Unfortunately, despite the many health benefits that are associated with walking, walking in Nigeria is at its lowest proportion. The perception held by Nigerian youths towards this rewarding exercise is a factor that needs urgent redress. This notwithstanding the deplorable state of our road facilities and paucity of pedestrian traffic consideration puts safety as a concern in the mind of any willing individual who would be interested in walking.

When cars collide with pedestrians, there is a high potential for serious injury. Pedestrian motor problems are a serious problem in Nigeria. Generally, pedestrian deaths are higher in the urban areas than in the rural areas. However, there is a higher ratio of deaths to injuries in rural areas because of impact of higher speeds on rural roads. However, pedestrian accidents occur most frequently in the urban areas. A demography of pedestrian related accidents shows that young people and the elder lies are the most vulnerable for pedestrian related injuries. Elderly pedestrians, although struck less frequently are the more likely to die after being struck by a vehicle. Although a substantial amount of accidents occur at intersections, a good number of pedestrian accidents also occur at locations other than intersections. This can be attributed to one or more of the following reasons.

I. Over speeding: Speeding is a major contributing factor in motor vehicle accidents of all types and has serious consequences when a pedestrian is involved. The fact that most drivers on a highway are not expecting when speeding therefore they are unlikely to see a pedestrian and even less likely to stop in time to avoid hitting pedestrian. It is noteworthy that a pedestrian has an $85 \%$ chance of death when involved in a motor/vehicle collision at $40 \mathrm{mph}$, a $45 \%$ percent chance of death at $30 \mathrm{mph}$ and a $5 \%$ chance of death at $20 \mathrm{mph}$.

II. Negligence: This could be due to a negligent driver or negligence from the pedestrian. Some common negligent practices by motorist include; failure to observe posted speed limits, failure to yield the right of way to pedestrians at marked cross walks, and disregard for traffic control devices.

III. Inattentiveness: Inattentiveness of an automobile or motorcycle driver is another major cause of pedestrian accidents. This could be as a result from talking on cell phones, eating while driving, applying make-up, or a variety of other activities.

IV. Driver confusion: This is common where a driver is unfamiliar with the territory or when a one-way street is involved.

V. Aggressive driving: Common in busy cites because drivers are more likely to violate traffic signals and display fits of road rage that results in unsafe speeds and unlawful turning.

VI. Ignorance by pedestrians: Pedestrians can be responsible for danger whenever they choose vehicles, wear dark clothes at night or attempt to disrupt the normal flow of vehicles.

VII. Poor night visibility: Lack of street lightning reduces night visibility. Sometimes the glare from headlights of vehicles makes it even more difficult for pedestrians to see.

VIII. Intoxication: Alcohol and drugs involvement for drivers and pedestrians was reported for $49 \%$ of the traffic crashes that resulted in pedestrian deaths. When one is drunk he loses the ability to give sound judgment to issues and these can result in inaccurate decisions either to cross when not supposed to by pedestrians or impaired vision in drivers resulting in pedestrian crashes. $^{3}$

IX. The above listed factors are some of the major causes of pedestrian accidents on the highway and they can invariably be categorized as some of the leading challenges to an individual who plans to take a walk by the road. Apart from the Engineering aspects which this study set to address, pedestrians need be aware of these potentials for danger whenever they take to the roads, and must do their part to observe safety.

\section{Collection of pedestrian traffic information}

As a way to explain the current status of the transportation system, engineers are required to collect diverse data and information. ${ }^{11}$ In this manner, focus is set in collecting data related to the volume of pedestrians in the system. Pedestrian volume data can have several applications, for example it could help to perform safety analysis studies, decide on modifications in infrastructure, and forecast future trends in society, business development among others. ${ }^{12}$ The collected data is the basis for planning, designing and decision making. ${ }^{11}$ Defined pedestrian volume as the number of persons passing a point 
during a specified time period. Volume patterns will differ significantly between different places (land uses), mainly because not all the various activities performed by the users are concentrated in one area. It has been found in previous studies that pedestrian volume patterns are specific ${ }^{7,12}$ which suggests that they are distinct to a particular place or location. Factors like time, land use and weather are taken into account when performing traffic volume studies generally. The locations at which pedestrian counts are needful include intersections, along sidewalks and mid-block crossings. ${ }^{13}$

\section{The selected survey locations}

The Awka is a fast developing city. Interestingly, Awka is the capital of Anambra State, Nigeria. A boisterous city that prides itself as a center for hospitality and commerce. It is not surprising the number of big building structures of hotels, business plazas, residential quarters and institutions of learning that make up the city. Along the Onitsha-Enugu expressway, especially from the Aroma junction to Unizik Junction many important institutions and links to others exist. It connects the three busy junctions, Aroma, Regina and Unizik to many other major towns in Anambra extending onto Onitsha. This road extends up to Enugu state in Nigeria. The expressway is a twoway, three lane highway. Hence, it is characterized by a heavy volume of traffic daily. The street life in this particular area is characterized by being constantly active. This is an attractive area for pedestrians due to its availability of shops, restaurants and cafes where some people spend good time at different times of the day for various purposes.

This well planned, designed and constructed roadway is characterized by various major flaws which are characteristics of a typical Nigerian road. In the design of this roadway, the authorities and engineer has made very little and in most cases no provision for pedestrians' safety either on, above or beside the roadway.

\section{Methodology}

Pedestrian count survey was conducted along the Awka segment of Onitsha-Enugu expressway from Aroma to Unizik junction. The surveys were done on two weekdays, Monday and Friday, and on Saturday. The two weekdays chosen would be representative of the typical traffic characteristics of the other days whereas the Saturday would necessary have a different traffic pattern for weekends. ${ }^{14,15}$ Traffic count of people was carried out over two; one hour period each day in the morning, $11 \mathrm{am}$ and $6 \mathrm{pm}$ in the evening at the three different locations namely: Aroma junction, Regina junction and Unizik junction. Manual method of counting was adopted for this survey. Demographic count of pedestrians crossing at the three junctions, and using the overhead bridge at Unizik junction, the time spent by pedestrians to cross the roads and the number of pedestrians that walked were obtained. The Highway geometric characteristics and dimensions were gotten by direct measurement using long measuring tapes.

\section{Results and discussion}

The traffic count was done to know how well policies relating to pedestrians is working efficiently and to formulate recommendable policies if such is lacking. Tables 1-3 below presents the raw traffic count data at the Aroma, Regina, and Unizik locations respectively. The alphabets Y, E, and C stands for youths, elderly, and children respectively.

Table I Pedestrian and vehicular traffic count at aroma junction

\begin{tabular}{|c|c|c|c|c|c|c|c|c|c|c|c|c|c|c|c|c|}
\hline \multirow{3}{*}{$\begin{array}{l}\text { Day of the } \\
\text { week }\end{array}$} & \multicolumn{8}{|c|}{ Pedestrians (Morning) } & \multicolumn{8}{|c|}{ Pedestrians (Evening) } \\
\hline & \multicolumn{3}{|c|}{ Crossings } & \multicolumn{3}{|c|}{ Walking } & \multicolumn{2}{|c|}{ Vehicles } & \multicolumn{3}{|c|}{ Crossings } & \multicolumn{3}{|c|}{ Walking } & \multicolumn{2}{|l|}{ Vehicles } \\
\hline & $Y$ & E & $\mathrm{C}$ & Y & $\mathrm{E}$ & C & Turning & Straight & Y & $\mathrm{E}$ & C & Y & E & C & Turning & Straight \\
\hline Wednesday & 812 & 16 & 25 & 120 & 3 & 54 & 2536 & 1253 & 1226 & 20 & 15 & 159 & 8 & 3 & 3192 & 1498 \\
\hline Friday & 1005 & 14 & 39 & 155 & 2 & 5 & 1798 & 817 & 1023 & 12 & 25 & 140 & 0 & 10 & 2370 & 940 \\
\hline Saturday & 917 & 6 & 59 & 127 & 0 & 10 & 1803 & 886 & 1386 & 3 & 16 & 186 & 0 & 4 & 1576 & 726 \\
\hline
\end{tabular}

Table 2 Pedestrian and vehicular traffic count at regina junction

\begin{tabular}{|c|c|c|c|c|c|c|c|c|c|c|c|c|c|c|}
\hline \multirow{3}{*}{ Day of the week } & \multicolumn{7}{|c|}{ Pedestrians (Morning) } & \multicolumn{7}{|c|}{ Pedestrians (Evening) } \\
\hline & \multicolumn{3}{|c|}{ Crossings } & \multicolumn{3}{|c|}{ Walking } & \multirow{2}{*}{$\begin{array}{l}\text { Vehicles } \\
\text { Straight }\end{array}$} & \multicolumn{2}{|c|}{ Crossings } & \multicolumn{4}{|c|}{ Walking } & \multirow{2}{*}{$\begin{array}{l}\text { Vehicles } \\
\text { Straight }\end{array}$} \\
\hline & $Y$ & $\mathrm{E}$ & C & $\mathrm{Y}$ & $\mathrm{E}$ & C & & Y & $\mathrm{E}$ & C & Y & E & C & \\
\hline Wednesday & 612 & 3 & 17 & 109 & 0 & 25 & 995 & 1089 & 3 & 7 & 127 & 10 & 1 & 1875 \\
\hline Friday & 572 & 5 & 17 & 156 & 5 & 35 & 988 & 889 & 10 & 12 & 173 & 0 & 0 & 915 \\
\hline Saturday & 541 & 22 & 29 & 156 & 3 & 24 & 1393 & 558 & 13 & 6 & 127 & 2 & 3 & 1290 \\
\hline
\end{tabular}

Table 3 Pedestrian and vehicular traffic count at unizik junction

\begin{tabular}{|c|c|c|c|c|c|c|c|c|c|c|c|c|c|c|c|c|}
\hline \multirow{3}{*}{$\begin{array}{l}\text { Day of the } \\
\text { week }\end{array}$} & \multicolumn{8}{|c|}{ Pedestrians (Morning) } & \multicolumn{8}{|c|}{ Pedestrians (Evening) } \\
\hline & \multicolumn{3}{|c|}{ Crossings } & \multicolumn{3}{|c|}{ Walking } & \multirow[t]{2}{*}{$\begin{array}{l}\text { Pedestrian } \\
\text { bridge }\end{array}$} & \multirow{2}{*}{$\begin{array}{l}\text { Vehicles } \\
\text { Straight }\end{array}$} & \multicolumn{2}{|c|}{ Crossings } & \multicolumn{4}{|c|}{ Walking } & \multirow[t]{2}{*}{$\begin{array}{l}\text { Pedestrian } \\
\text { bridge }\end{array}$} & \multirow[t]{2}{*}{$\begin{array}{l}\text { Vehicles } \\
\text { straight }\end{array}$} \\
\hline & Y & E & $\mathrm{C}$ & $Y$ & E & C & & & $Y$ & E & $\mathrm{C}$ & Y & $\mathrm{E}$ & $\mathrm{C}$ & & \\
\hline Wednesday & 422 & 22 & 47 & 169 & 10 & 35 & 1099 & 1190 & 689 & 23 & 7 & 187 & 18 & 5 & 1385 & 1075 \\
\hline Friday & 579 & 0 & 3 & 133 & 2 & 7 & 887 & 1386 & 735 & 0 & 4 & 166 & 4 & 13 & 1070 & 1236 \\
\hline Saturday & 1001 & 0 & 31 & 158 & 2 & 10 & 1233 & I 236 & 781 & 0 & 5 & 189 & 7 & 5 & 1040 & I 773 \\
\hline
\end{tabular}


This result shows a very high proportion of pedestrian movement at the study locations. Pedestrians were mostly interested in crossing than walking along the expressway. The crossing movements were intended to get to the other side of the highway. This has obvious difficulties, as special arrangement for crossing was made at the Unizik junction alone by the provision of an overhead pedestrian bridge.

The highest vehicular traffic flow was observed on Wednesday evenings at Aroma, which was as high as $4690 \mathrm{Veh} / \mathrm{hr}$ for both straight ahead movements and turning. The pedestrian volume of 1431 at Aroma at this time is also quite very high pointing to the fact that crossing difficulties would be experienced by pedestrians at that intersection. It is quite unfortunate, that most traffic control infrastructures provided at Aroma over the years have been targeted at vehicular traffic movement efficiency alone. No pedestrian priority sections, signaling, or separate walkways. The design of this expressway as well as most Nigerian roads could be defined as a solely vehicle minded design. This design is socially not stainable as they not only delay and discourage pedestrians, but also put their lives in danger when crossing or walking becomes inevitable.

At Unizik junction, the average time required for a pedestrian to cross the roadway using the pedestrian bridge was estimated at 3 minutes only. From the Table 3 above, it was clear that more pedestrians preferred to use the bridge than to cross the road on the carriageway, jumping the large trapezoidal central drainage ditch. It shows that majority of pedestrians are actually safety conscious. For some reasons, up to $34 \%$ of the pedestrians (using Wednesday evening as a case study) still prefers to cross on the carriageway. The average time spent to cross the busy road directly was observed to be approximately 50 seconds excluding the waiting time before initial crossing. The difficulties of jumping the drainage as well as beating fast approaching vehicles are actually phenomenal at this location.

These difficulties are much pronounced at the Regina junction, with the least pedestrian traffic among these three locations, but absolutely zero pedestrian crossing friendliness. The fact that pedestrians are, up till the time of this reporting, left with no other option than to cross the road with an average carriageway with of $33 \mathrm{~m}$ and a central drainage ditch of about $2.7 \mathrm{~m}$ opening. This is a very serious issue, considering the fact that there are children and aged people demanding to cross the road at this location. A very zero consideration of accessibility even for disabled pedestrians is tantamount to a poor engineering design and inconsiderate provision of public facility. The pedestrian bridge located at the Unizik junction is quite far, a distance of approximately $1 \mathrm{~km}$ is quite much for someone to walk before crossing on the bridge and walking back the same distance, especially when time is a serious factor. This suggests why all the pedestrian crossings at Regina were done on the carriageway, despite the risk and difficulties.

The summary of all the observed difficulties faced by pedestrians his highway both crossing difficulties and walking difficulties include;

a. Uneven or no sidewalks or walkway: A walkways is one of the safest part of the road for pedestrians to use when moving from one place to another. It could be at the central reserve or by the verge or kerb side of the road. But these pedestrian friendly aspects of the road design have been occupied by very widely open trapezoidal or rectangular drainage channels which if closed could have ultimately served also as walkways. Sidewalks where they exist are uneven, unpaved and sometimes covered with tall grasses due to poor maintenance. Pedestrians, hence, are forced to walk on the carriageway of the busy roads which is unsafe for them. These could have contributed to the much lesser number of children and elderly pedestrians on this highway.

b. Moving on busy roads: The high volume of traffic carried by trunk A roads like the Onitsha-Enugu expressways requires a total separation of pedestrian traffic, in form of priority areas or pedestrian lanes. But this is not provided, making pedestrian safety subject to the pedestrian's level of consciousness and alertness.

c. No traffic signal and signs: Along the length of this very busy road, we could find no traffic signs and no traffic signaling device. No signal device to control the movement of vehicles and also allow for ease of movements by pedestrians especially at the intersections. Traffic wardens who control traffic at the Aroma junction were conspicuously absent on two (2) occasions. Besides, even in times when they are present, they were observed to be totally after vehicular traffic with no concern about the crossing pedestrians. At all locations along this highway, the pedestrians had to stressfully look round, calculate and arrive at very precise decisions on when to cross the road. Exposed to risk of being hit by moving vehicles.

d. No road markings: Road markings are traffic signs in the form and design of a marking on the surface of the road. This item of aesthetics on roadways which helps to direct the flow and direction of traffic need to be obeyed by road users. They could be in form of solid white lines used to indicate kerbside parking, pedestrian, bicycle lanes and other features. Zebra marks used to give priorities to right of way to pedestrians are conspicuously missing all along the case study road. This is very worrisome because children and the elderly would have utilized these greatly for their safety.

e. Poor night lighting: Night visibility in these roads is very poor. This is due to the fact that there are no street lights found in the whole length of the road. Pedestrians are exposed to all sort of hazards ranging from robbery, accidents or hitting ones foot on hard objects. Most pedestrian deaths that occur in urban nonintersection locations occur at night. Visibility of both drivers and pedestrians are reduced at this time. The visibility of pedestrians are reduced by glare from head lights of vehicles, likewise the visibility of vehicles are reduced because of lack of street lights and glare from other incoming vehicles at the other opposite lanes.

f. Speeding by drivers and motorist: This is a common feature on Nigerian roads both in the rural and urban areas. Motorists take advantage of the fact that there are no speed limits on our highways to over speed regardless of their destination. They blow their horns when over speeding in a way to scare off pedestrians when moving. This act they do with much indifference to the possibility of sick, children or elderly pedestrians and other road users.

g. Ugly road scenery, lack of sit outs and shades: The roads were built without consideration to aesthetics. A beautiful place or surrounding attracts people to it. Absence of flowers, trees or any feature whatsoever along these roads makes it a burden on pedestrians to use. Sit outs and shades make walking relaxing and interesting. For example, while walking, when a person gets tired he/she may desire to sit and rest before continuing the journey or while waiting to board a vehicle. Two bus stop 
shades exist at one side of the road within the study segment. These are not really being utilized by the pedestrians as they are not well taken care of. Always dusty and located far away from the carriageway edge.

h. Screening by physical objects: Pedestrian crashes become more likely when motorist and pedestrians cannot see they are on intersecting paths. Screening can occur as a result of parked vehicles, electric poles, billboards and other things blocking sight distance of pedestrians when attempting to cross the road.

i. Vehicles stopping behind pedestrians: It was observed that vehicles indiscriminately stopped behind pedestrians when they wanted to alight or pick a passenger by the road.

j. Insults from drivers: Drivers were of the habit to insult and curse at pedestrians, sometimes molesting the pedestrians with their cars by threatening to knock them down. This reduces pedestrian confidence making it feel inferior to walk.

k. Absence of pedestrian bridges: Along this major highway, as pointed earlier, only one pedestrian bridge exists within Awka. We observed that the pedestrian bridge at that junction was maximally utilized by the pedestrians to cross the highway. These reduced the risk associated with crossing the highway, jumping in and out of the drainage ditch at the center of the road when attempting to cross the road. But there is none at all other locations within Awka. Besides, about 34\% of pedestrians fail to use the bridge at the Unizik junction. This is quite a significant proportion, which called for interview at that location. Some of the identified deterrence to the use of pedestrian bridge at this location include; time saving, fatigue for climbing the bridge stairs, congestion on the bridge due to hawking activities which has reduced the capacity of the bridge as well as large volume of pedestrians, fear for anticipated robbery attack at night, etc.

\section{Conclusion and proposed solutions}

It is certain, from this study, that the difficulties faced by pedestrians within Awka, along the Onitsha-Enugu Expressway are enormous and can only be solved or improved by concerted efforts from both governmental and non-governmental institutions. These steps would require a great deal of time and money. It is expected that to achieve this would require the government to engage in massive infrastructural rehabilitation, city or road beautification, law enforcement and nationwide sensitization. The following solutions have been proposed to some of the listed challenges.

I. Improved design and materials of the roadway: This is aimed at reducing pedestrian exposure to vehicular traffic. Some of the most important categories of engineering improvement and changes that can be made to the roadway would involve the construction of modern roundabouts in major places of intersections and stops. Rehabilitation of damaged road pavements is also quintessential. Construction of sidewalks/ walkways must be made paramount both for existing roads and subsequent projects. Construction of more overpasses i.e. pedestrian bridges will be targeted at all locations of high pedestrian traffic as well as other pedestrian friendly highway features like underpasses, central islands, kerb ramps, etc.

II. Implement lighting/crosswalk illumination measures: Good placement of lighting levels can enhance an environment for walking, as well as increase pedestrian safety and security.
Pedestrians often assume they can be seen by motorist at night since they can see the oncoming headlights. Therefore emphasis is needed on providing the driver the help needed to see the pedestrian in time to stop. Some measures to achieve these objectives are; installation of staged street lights, refurbishment of the cat eyes among others.

III. Implementation of operating speed limits at the busy road sections: Speed limiting devices should be introduced on the highway at places that makes them noticeable to motorist especially at areas of frequent road crossings and at intersections. Examples of this include; speed humps, rotary, stop signs, posted speed limit signs, etc.

IV. Discouragement of kerb side parking: Street parking on carriageways leads to screening and obscurity of pedestrian's angle of sight when crossing the roads. This is an enforcement strategy recommended for the Anambra State Traffic Management Agency (ATMA).

V. Public information and highway education programs: The primary target of this exercise would be to reach an audience consisting of road users at a particular location. The media can also be effectively utilized to educate motorist and pedestrians on safety measures when walking or crossing the highway. The education program should comprise of sensitization lectures on the importance of walking, associated needs, support services on the roadway for safety and other relevant information derived from researches that would encourage walking and ensure that difficulties experienced by pedestrians are reduced to the minimum.

VI. Enforcement of traffic laws: Well designed and managed enforcement programs can have a significant positive effect on highway safety. The laws exist in Nigeria but the enforcement agencies have not been efficient in the implementation of the regulations.

This measures as listed above require a huge amount of finance and cost from government and pedestrians. But safety in any activity should be given priority. If these measures are implemented to the fullest, it will surely increase the number of pedestrians and ensure the safety of these people. Children, the elderly and all categories of people including the disabled would respond by using the facilities provided to walk, skate etc.

\section{Recommendations}

A key performance measure for effectiveness and efficiency of our roadway should be the frequency and percentage of pedestrian who are found using the roadway. An increase in the proportion of pedestrian traffic that is walking, cycling, skating and other activities involving both children and the elderly, able and disabled etc. maybe a successful measure to determine the perceived convenience and safety of pedestrians on our roadway.

\section{It is therefore recommended that:}

i. Government agencies must overcome decades of street and road construction projects that have routinely ignored the provision of sidewalks and walkways. Pro-pedestrian policies and construction programs need to be approved and corrected to correct this problem.

ii. Legislation need be put in place that would ensure safety of pedestrians on the roadway. 
iii. Street furniture should be positioned along the roadway.

iv. Performance measures of various roadway facilities should be investigated. Further researches on difficulties faced by pedestrians should be conducted and properly documented for purpose of policy making. Public hearings may be conducted to this effect.

v. Statistics of pedestrian related crashes should be gathered by the relevant federal and state agencies and be made available for academic and research purposes. These studies need to be regularly published in the media to create a greater awareness on the dangers of improper use of roadway facilities in the populace.

\section{Acknowledgements}

None.

\section{Conflict of interest}

The author declares no conflict of interest.

\section{References}

1. Federal Highway Administration. Pedestrian and Bicycle Data Collection. US Department of Transportation HPPI-30, AMEI E \& I, Inc; 2011.

2. Allison DB, Kelvin RF, Joann EM, et al. Annual Deaths Attributable to Obesity in the United States. JAMA. 2005;282(16):1530-1538.

3. National Highway Traffic Safety Administration. Traffic Safety Facts; Data on Pedestrians. US Department Of Transportation, National Highway Traffic Safety Administration Washington, Dc. Publication No. DOT-HS-812-124; 2015 .
4. Button K. Transport Economics. 3rd ed. UK: Edward Elgar, Cheltenham; 2010.

5. Rogers M. Highway Engineering. 2nd ed. UK: Blackwell Publishing; 2012.

6. Department for Transport. Rules for Pedestrians. The UK Highway Code-Guidance. London: Her Majesty Press Office; 2016. p. 1-35.

7. Edwards AS, Jorge GY. Pedestrian Volume Studies. Master of Science Thesis in Geo and Water Engineering. Sweden: Chalmers University of Technology; 2011.

8. John B. Pedestrian Accident Statistics. Law Information. 2008

9. PM News Nigeria. More Than 270000 Pedestrians Killed Yearly. 2013.

10. Seun A. Death on the Highway. Nigeria: Published On The Nation Newspaper; 2014.

11. Roess RP, Prassas ES, Mcshane WR. Traffic Engineering. 3rd ed. New Jessy: Pearson Prentice Hall; 2004.

12. Schneider R, Arnold L, Ragland D. A Methodology for Counting Pedestrians at Intersections: using Automated Counters to Extrapolate Weekly Volumes from Short Manual Counts (Revised). Berkeley: University of California; 2008.

13. Alutman Hall L, Lane D, Lambert RR. Assessing the Impact of Weather and Season on Pedestrian Traffic Volumes. Report of the Transportation Research Board (TRB), University of Vermont; 2009.

14. Garber NJ, Hoel LA. Traffic and Highway Engineering. 3rd ed. USA: Brooks/Cole Thompson Learning, University of Virginia; 2002.

15. Robertson HD, Hummer JE, Nelson DC. Manual of Transportation Engineering Studies. New Jersey: Prentice Hall and the Institute of Transportation Engineers (ITE); 1994. 